\title{
First observation of Chapman rearrangement of a pseudosaccharyl ether in the solid state: the thermal isomerization of 3-(methoxy)- 1,2-benzisothiazole 1,1-dioxide revisited
}

\author{
R. Almeida ${ }^{\mathrm{a}, \mathrm{b}}$, A. Gómez-Zavaglia ${ }^{\mathrm{a}, \mathrm{c}}$, A. Kaczor ${ }^{\mathrm{a}, \mathrm{d}}$, M.L.S. Cristiano ${ }^{\mathrm{b}}$, \\ M.E.S. Eusébio ${ }^{\text {a, T.M.R. Maria }}{ }^{\text {a }}$, R. Fausto ${ }^{\text {a, } *}$

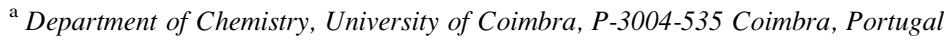 \\ ${ }^{\mathrm{b}}$ Department of Chemistry and Biochemistry, F.C.T. and CCMAR, University of Algarve, P-8005-039 Faro, Portugal \\ ${ }^{\mathrm{c}}$ Faculty of Pharmacy and Biochemistry, University of Buenos Aires, C.P. 1113 Buenos Aires, Argentina \\ ${ }^{\mathrm{d}}$ Faculty of Chemistry, Jagiellonian University, Ingardena 3, 30-060 Krakow, Poland
}

Received 24 May 2007; received in revised form 13 November 2007; accepted 5 February 2008

Available online 7 February 2008

\begin{abstract}
3-(Methoxy)-1,2-benzisothiazole 1,1-dioxide, a pseudosaccharyl ether, was long ago known to undergo a thermal Chapman-like [1,3']-isomerization to the corresponding $N$-methyl pseudosaccharin at temperatures above its melting point (ca. $\left.184{ }^{\circ} \mathrm{C}\right)[\mathrm{Hettler} \mathrm{H}$., Tetrahedron Lett. 1968, 15, 1793]. In the present study, it is shown that this rearrangement can also take place in the solid state, at temperatures as low as $150{ }^{\circ} \mathrm{C}$. This was the first observation of a Chapman-like $\left[1,3^{\prime}\right]$-isomerization in pseudosaccharyl ethers in the solid state. The study has been carried out by a multidisciplinary approach using temperature dependent infrared spectroscopy, differential scanning calorimetry (DSC), and polarized light thermomicroscopy, complemented by theoretical methods.
\end{abstract}

(c) 2008 Elsevier Ltd. All rights reserved.

Keywords: Pseudosaccharin; 3-(Methoxy)-1,2-benzisothiazole 1,1-dioxide; Chapman rearrangement; DFT calculations; Infrared spectroscopy; DSC; Thermomicroscopy

\section{Introduction}

Benzisothiazoles are important heterocyclic compounds due to their major applications in crucial areas. Saccharin (1,2-benzisothiazol-3(2H)-one-1,1-dioxide) is a commonly known substance as it is the oldest artificial sweetener. Isothiazolyl derivatives receive an increased attention as they show herbicidal, ${ }^{1,2}$ antimicrobial, and antifungal activity $^{3-5}$ or potential in enzymatic inhibition. ${ }^{6}$ Also, the first non-benzoannelated 4-amino-2,3-dihydroisothiazole 1,1-dioxide, lacking a 3-oxo group, has recently been described and shows antiHIV-1 activity. ${ }^{7}$ Benzisothiazoles are also very important in organic and bioorganic synthesis. Saccharin itself has been

\footnotetext{
* Corresponding author. Tel.: +351 239 852080; fax: +351 239827703.

E-mail address: rfausto@ci.uc.pt (R. Fausto).
}

frequently used as a key structural element of industrially developed biologically active compounds ${ }^{5,8,9}$ and has long been established as a cheap and versatile starting material for the synthesis of related heterocyclic derivatives. By their side, substituted 1,2-benzisothiazole 1,1-dioxides (pseudosaccharins) have also been shown to be important intermediates in organic synthesis. For instance, their $O$-ethers provide efficient intermediates for reductive cleavage of the $\mathrm{C}-\mathrm{O}$ bond in phenols, ${ }^{10}$ benzylic, ${ }^{11}$ and naphthylmethylic alcohols, ${ }^{12}$ through heterogeneous catalytic transfer hydrogenolysis or through cross-coupling with organometallic reagents. ${ }^{13,14}$ The structural basis of the enhanced reactivity of pseudosaccharyl ethers toward transition metal-catalyzed ipso-replacement lies in the unusual geometry of their $\mathrm{C}_{\mathrm{R}}-\mathrm{O}-\mathrm{C}_{\mathrm{A}}$ linkage (where $\mathrm{R}=$ heteroaromatic ring and $\mathrm{A}=$ aliphatic or aryl group). Indeed, the strong withdrawing effect of the pseudosacharyl group 
results in significant lengthening of the $\mathrm{C}_{\mathrm{A}}-\mathrm{O}$ bond at the expense of the $\mathrm{C}_{\mathrm{R}}-\mathrm{O}$ bond, which gains partial double-bond character. $^{11,12,15-18}$ This characteristic structural feature of pseudosaccharyl ethers, which is directly related to the potential of the pseudosaccharyl-oxygen system as nucleofuge in transition metal-catalyzed reductive cleavage, is certainly also important in other reactions that involve cleavage of the weak $\mathrm{C}_{\mathrm{A}}-\mathrm{O}$ bond, such as the Chapman-like thermal isomerization of 3-alkoxy-pseudosaccharins (Scheme 1).

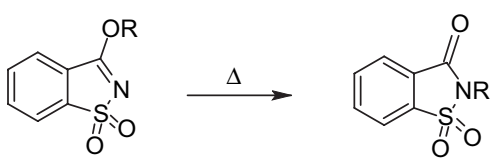

Scheme 1. Chapman rearrangement of alkyl pseudosaccharyl ethers ( $\mathrm{R}=$ alkyl).

The thermal conversion of aryl iminoethers into $N$-aryl amides is known generically as the Chapman rearrangement ${ }^{19,20}$ and represents a valuable synthetic strategy for $\mathrm{N}$-arylation, leading for instance to the preparation of amides. ${ }^{21-24}$ This methodology has even been applied in polymer chemistry, enabling the easy preparation of thermally stable polyamides from polyimidates. ${ }^{25}$ The intramolecularity of the aryl migration was postulated by Chapman, and further confirmed by Rowland $^{26}$ and Wheeler ${ }^{27}$ through cross-over and isotopic labeling studies, respectively. Aryl migration is thought to occur via a four-membered cyclic transition state, and consists in a nucleophilic ipso-replacement of $\mathrm{O}$ by $\mathrm{N}$, at the arylic carbon. An investigation by Relles $^{28}$ revealed that this migration benefits from steric rate enhancement when the migrating aryl bears substituents in ortho position, provided that these do not lead to relevant steric compression. However, for alkyl imidates, intramolecular $\mathrm{O}-$ to $\mathrm{N}$ - migration of the alkyl group is not feasible on stereoelectronic grounds, and therefore the mechanism is usually assumed to be intermolecular. ${ }^{29}$ Electrophilic reagents such as alkyl iodide are often used to induce initial alkylation of the nitrogen, producing a quaternary salt from which cleavage of the $\mathrm{C}-\mathrm{O}$ bond is much easier. This strategy has been widely applied for instance in the easy isomerization of 5-( $N$-methylpyridinium-2-oxy)-1-phenyltetrazole to 4-(Nmethylpyridinium-2-yl)-1-phenyltetrazole-5-one, a key step in the synthesis of 2-aminopyridines from $2(1 H)$ pyridones. ${ }^{30} \mathrm{Un}$ catalyzed migration of alkyl has been investigated, for instance, in 2-alkoxypyridines, ${ }^{31}$ 1-alkoxy-5-aryltetrazoles, ${ }^{32}$ 2,4,6-trimethoxy-1,3,5-triazine, ${ }^{33}$ and 5-methoxy-2-aryl-1,3,4-oxadiazoles. $^{34,35}$ In this last system, Chapman isomerization was observed with the neat melted compounds and also in the crystalline phase, where it was found to be comparatively much easier. $^{34,35}$ The observed ease of rearrangement in the solid state was justified by solid-state analysis and ascribed to a suitable arrangement of the molecules in the crystal, leading to an intermolecular 'domino' methyl transfer process. ${ }^{34}$

The Chapman isomerization of 3-alkoxy-pseudosaccharins, including the simplest member of this family, 3-(methoxy)1,2-benzisothiazole 1,1-dioxide (MBID), has been previously observed by Hettler, ${ }^{36}$ in the course of an investigation on the thermal reactivity of several derivatives of 5-chloro-1,2benzisothiazole 1,1-dioxide (pseudosaccharyl chloride). ${ }^{37-39}$ Four pseudosaccharyl ethers were found to undergo a Chapman isomerization, when heated above their melting points. ${ }^{36}$ In the case of MBID (mp $\sim 184^{\circ} \mathrm{C}$ ), conversion was considered to be completed in $70 \mathrm{~min}$, at $190^{\circ} \mathrm{C}$. When this saccharyl derivative was rearranged in the presence of ethyl iodide, a mixture of $N$-ethyl and $N$-methyl saccharin was formed. This result is in agreement with the previously observed catalytic effect of electrophilic reagents, via alkylation on nitrogen, and also with the proposed intermolecular nature of this Chapman isomerization. ${ }^{36}$

In the present study, the Chapman isomerization of 3(methoxy)-1,2-benzisothiazole 1,1-dioxide (MBID) was reinvestigated by a multidisciplinary approach, using temperature dependent infrared spectroscopy, differential scanning calorimetry (DSC), and polarized light thermomicroscopy, complemented by theoretical methods. It is now demonstrated that the Chapman isomerization of MBID occurs not only in the melted phase, but it proceeds also very smoothly in the crystalline state, starting to take place at a clearly observable rate at a temperature as low as $150{ }^{\circ} \mathrm{C}$. To the best of our knowledge, this is the first observation of a Chapman-like [1, $\left.3^{\prime}\right]$-isomerization in pseudosaccharyl ethers in the solid state.

\section{Experimental and computational methods}

\subsection{General}

MBID (Fig. 1a) was synthesized from 3-chloro-1,2-benzisothiazole-1,1-dioxide (pseudosaccharyl chloride), through solvolysis as described in Ref. 18 (62\% yield; mp 184$\left.185^{\circ} \mathrm{C}\right) .{ }^{1} \mathrm{H}$ NMR $\left(300 \mathrm{MHz}, \mathrm{CDCl}_{3}\right): \delta 4.20(3 \mathrm{H}, \mathrm{s}), 7.67-$ $7.80(3 \mathrm{H}, \mathrm{m}), 7.87-7.90$ (1H, d); MS (EI): $\mathrm{m} / \mathrm{z} 197\left([\mathrm{M}]^{+}\right.$, $22 \%$; see also Supplementary data). The $N$-methyl isomer of MBID [2-methyl-1,2-benzisothiazol-3(2H)-one 1,1-dioxide (MBIOD); Fig. 1b] was obtained from MBID, by heating a neat sample at ca. $185^{\circ} \mathrm{C}$ and keeping the sample at this temperature until all reactant has disappeared, as confirmed
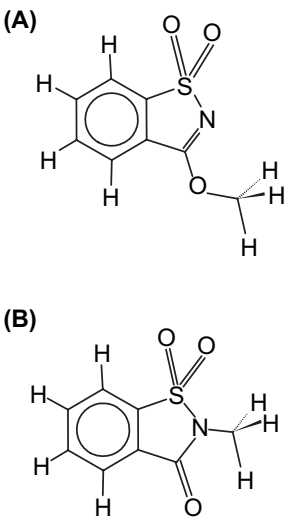

Figure 1. Structures of (a) 3-methoxy-1,2-benzisothiazole 1,1-dioxide (MBID) and (b) 2-methyl-1,2-benzisothiazol-3(2H)-one 1,1-dioxide (MBIOD). 
by TLC analysis; mp $129-130{ }^{\circ} \mathrm{C} .{ }^{1} \mathrm{H}$ NMR $(300 \mathrm{MHz}$, $\left.\mathrm{CDCl}_{3}\right): \delta 3.28(3 \mathrm{H}, \mathrm{s}), 7.80-7.90(2 \mathrm{H}, \mathrm{m}), 7.92-7.96(1 \mathrm{H}$, d), 8.05-8.10 (1H, d). MS (EI): $\mathrm{m} / z 197\left([\mathrm{M}]^{+}, 100 \%\right.$; see also Supplementary data).

The infrared spectra, in the $500-4000 \mathrm{~cm}^{-1}$ range, were recorded for the compound diluted in a $\mathrm{KBr}$ pellet, using a Bomem MB104 FT-spectrometer, with $4 \mathrm{~cm}^{-1}$ resolution, and a SPECAC variable temperature infrared cell connected to a digital controller (Shinho, MCD 530), which enables to attain an accuracy in the temperature of ca. $\pm 1{ }^{\circ} \mathrm{C}$. The temperature was measured directly at the sample holder by an iron/constantan (copper-nickel) J-type thermocouple. The sample compartment of the spectrometer was purged during all experiments by means of a constant flux of dry nitrogen, to avoid contamination from absorptions due to atmospheric water and $\mathrm{CO}_{2}$.

Thermal studies were carried out on a Perkin-Elmer DSC7, a power compensation calorimeter with a CCA7 cooling unit, over the temperature range $25-210^{\circ} \mathrm{C}$, with scanning rate $10{ }^{\circ} \mathrm{C} \mathrm{min}{ }^{-1}$. Data acquisition and determination of the onset temperatures and transition enthalpies were performed with the Perkin-Elmer 1020 Series Thermal Analysis System Software. The samples were hermetically sealed in aluminum pans and as reference an empty pan was used. No sample weight loss occurred in any experiment. A $20 \mathrm{ml} \mathrm{min}^{-1}$ nitrogen purge was employed. Temperature calibration ${ }^{40}$ was performed with high grade standards namely biphenyl $\left(T_{\text {fus }}=68.93 \pm 0.03{ }^{\circ} \mathrm{C}\right)$ and zinc $\left(T_{\text {fus }}=419.53^{\circ} \mathrm{C}\right)$, and verified with naphthalene $\left(T_{\text {fus }}=80.20 \pm 0.04{ }^{\circ} \mathrm{C}\right)$, benzoic acid $\left(T_{\text {fus }}=\right.$ $\left.122.35 \pm 0.02{ }^{\circ} \mathrm{C}\right)$, and indium $\left(T_{\text {fus }}=156.60{ }^{\circ} \mathrm{C}\right)$. For heat calibration, the enthalpy of fusion of indium was used $\left(\Delta_{\text {fus }} H=3286 \pm 13 \mathrm{~J} \mathrm{~mol}^{-1}\right){ }^{40}$

The hot stage/DSC video microscopy study was carried out by means of a Linkam DSC600 system. The optical equipment attached to the hot stage system consists of a DMRB Leica microscope fitted with polarized light facilities to which a Sony CCD-IRIS/RGB video camera is attached. A Linkam system software with Real Time Video Measurement was used for image analysis. A small amount of the sample to be studied was placed in a glass crucible used as a cell, which was covered with a glass lid. Thermal cycles were followed by $200 \times$ magnification and the images obtained by combined use of polarized light and wave compensators. The thermal program for the microscope examination was run at $10{ }^{\circ} \mathrm{C} \mathrm{min}{ }^{-1}$. Biphenyl and benzoic acid were used to confirm temperature accuracy.

All geometry optimizations and calculations of the infrared spectra were performed at the recommended ${ }^{18}$ level of theory for pseudosaccharin compounds: DFT(B3LYP)/6-311++G(3df,3pd), ${ }^{41,42}$ using the Gaussian 03 program package. ${ }^{43}$

\section{Results and discussion}

\subsection{Infrared spectroscopic experiments and results of theoretical calculations}

The studied reactant molecule, 3-(methoxy)-1,2-benzisothiazole 1,1-dioxide (MBID) has been recently characterized structurally in our laboratories. ${ }^{18}$ It has been shown to have two conformers, differing in the relative position of the methoxy and saccharyl moieties. However, the relative energy of these two conformers is very large (ca. $\left.47 \mathrm{~kJ} \mathrm{~mol}^{-1}\right)^{18}$ and only the most stable conformer (depicted in Fig. 1a) is of practical interest. In our previous study, the infrared spectrum of the monomer of this compound has also been obtained theoretically at the DFT(B3LYP)/6-311++G(3df,3pd) level and compared with the experimental spectrum of the compound isolated in cryogenic inert matrices (at $10 \mathrm{~K}$ ). The agreement between the experimental and calculated spectra was found to be excellent, allowing a detailed analysis of the experimental data and, simultaneously, showing that the theoretical method selected is appropriate to be used in the structural and vibrational study of pseudosaccharins. ${ }^{18}$

In Figure 2a and $\mathrm{b}$ we compare the DFT(B3LYP)/ 6-311++G(3df,3pd) calculated infrared spectrum for the relevant conformational state of MBID with the spectrum obtained

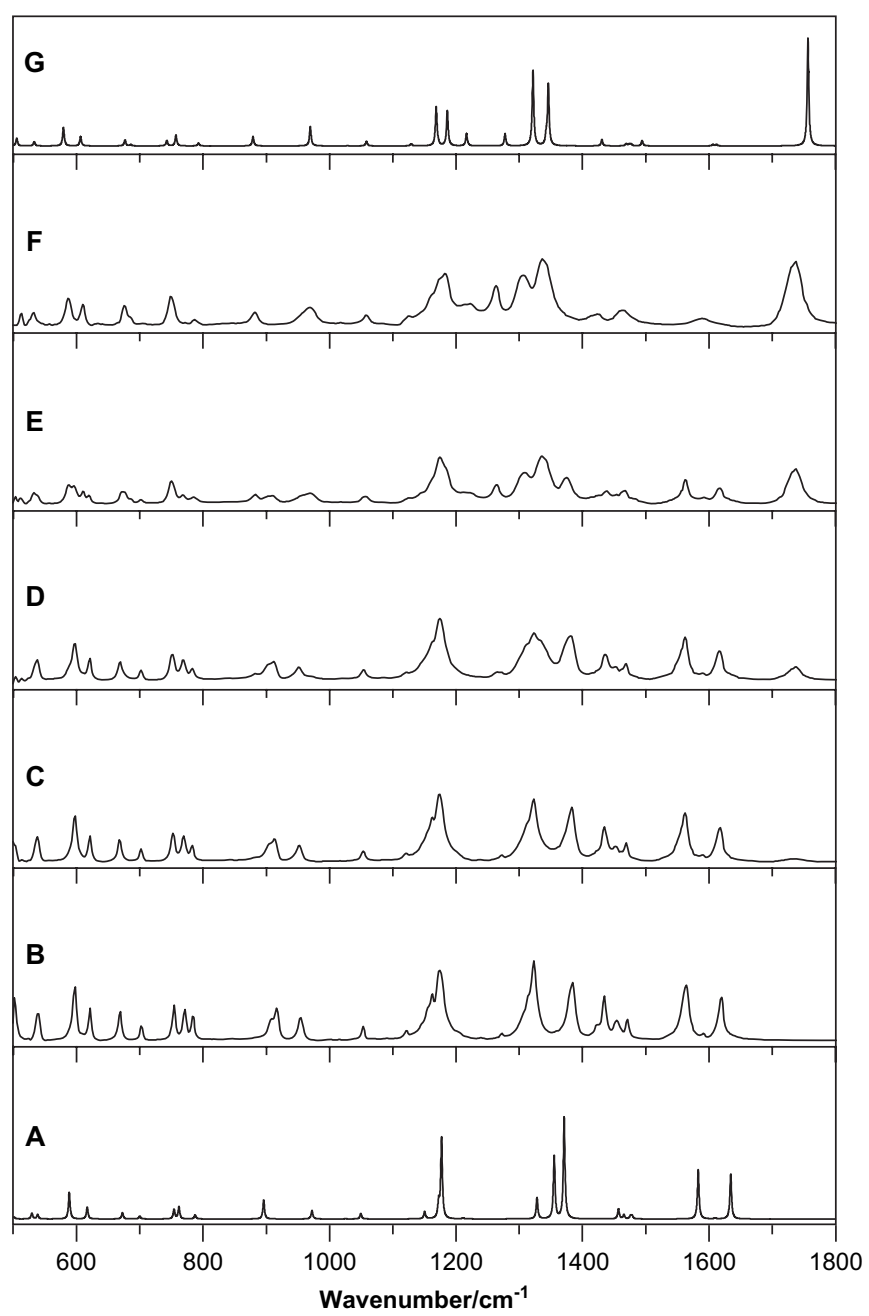

Figure 2. (a) Calculated [DFT(B3LYP)/6-311++G(3df,3pd)] infrared spectrum for MBID; (b) room temperature $\left(20^{\circ} \mathrm{C}\right)$ infrared spectrum of polycrystalline MBID in $\mathrm{KBr}$ pellet; $(\mathrm{c}-\mathrm{f})$ infrared spectra at different temperatures $\left(150,160,170\right.$ and $\left.210^{\circ} \mathrm{C}\right)$, obtained along the heating of MBID from room temperature, showing the conversion of this compound into MBIOD via Chapman rearrangement; $(\mathrm{g})$ calculated [DFT(B3LYP)/6-311++G(3df,3pd)] infrared spectrum of MBIOD. (Displayed spectral range: $500-1800 \mathrm{~cm}^{-1}$.) 
for the compound in the crystalline phase at room temperature. The close agreement between the two spectra is clearly evident from this figure, indicating that intermolecular interactions in the crystal are not strong enough to disturb significantly the intramolecular vibrational modes. Based on the theoretical data (and also on the previously reported data for the matrix-isolated compound ${ }^{18}$ ), the infrared spectrum of the crystalline phase of MBID could be easily assigned (Table 1 ).

Upon temperature increase, the spectrum of MBID loses intensity whereas new bands emerge. Traces $\mathrm{c}$ to $\mathrm{f}$ in Figure 2 correspond to spectra registered at different temperatures $\left(150,160,170\right.$ and $\left.210^{\circ} \mathrm{C}\right)$, during the heating of MBID up till the bands due to this compound completely disappear from the spectrum. These spectra were obtained using a temperature-raising program in which the temperature was increased as fast as possible (starting from room temperature) in increments of $10{ }^{\circ} \mathrm{C}$ and letting the sample to equilibrate at each temperature during ca. $5 \mathrm{~min}$. The new bands start to be clearly visible in the spectrum obtained at $150{ }^{\circ} \mathrm{C}$, which is rather far from the melting temperature of MBID $\left(\mathrm{ca} .184^{\circ} \mathrm{C}\right.$ ), indicating that the observed process starts taking place in the solid phase. The spectrum shown in trace $\mathrm{f}$ corresponds to a temperature of $210{ }^{\circ} \mathrm{C}$, i.e., clearly above the melting point of MBID, and does not exhibit signs of presence of this compound. So, it can be concluded that at that point the observed process was already completed and the observed spectrum corresponds to the reaction product.

According to the expectations, the obtained product should be the $N$-methyl isomer of MBID [2-methyl-1,2-benzisothiazol-3(2H)-one 1,1-dioxide (MBIOD); Fig. 1b], resulting from the Chapman rearrangement of the methyl pseudosaccharin ether. In order to check this, we performed several experiments.

The first one consisted in predicting theoretically the infrared spectrum of MBIOD (which is a molecule possessing only one conformer) and then comparing it with the experimental spectrum obtained after the observed thermal process was completed. This theoretical spectrum is shown as trace $\mathrm{g}$ in Figure 2. As can be observed, the theoretical spectrum matches closely the experimental one, confirming MBIOD as the product resulting from the observed thermal process.

A second and even more conclusive experiment was undertaken, where the spectrum shown in trace $\mathrm{f}$ of Figure 2 was compared with the spectrum of the independently synthesized and duly characterized crystalline MBIOD. These two spectra are shown in Figure 3 (a and b, black lines). As seen in this figure, though being similar and easily ascribed to the same chemical species, the two spectra do not match perfectly. Indeed, the spectrum obtained at the end of the experiment whose progress is shown in Figure 2 (trace $f$ in that figure, which is now repeated in Fig. 3a) appears to be identical to the one obtained directly from the MBIOD sample at temperatures above the melting point of this compound (ca. $129^{\circ} \mathrm{C}$ ), i.e., identical to the spectra drawn in blue and violet in Figure 3b. Such result can easily be explained if we notice that MBIOD is produced from MBID at temperatures above its melting point. However, after leaving
Table 1

Assignment of experimental IR spectra of polycrystalline MBID in $\mathrm{KBr}$ pellet (500-4000 $\mathrm{cm}^{-1}$ spectral range)

\begin{tabular}{|c|c|c|c|c|}
\hline \multicolumn{2}{|c|}{$\begin{array}{l}\text { Calculated }^{\mathrm{a}} \\
\text { B3LYP/6-311 } \\
++\mathrm{G}(3 \mathrm{df}, 3 \mathrm{pd})\end{array}$} & \multicolumn{2}{|c|}{$\begin{array}{l}\text { Experimental } \\
\text { (polycrystalline; } \\
\text { KBr pellet) }\end{array}$} & \multirow[t]{2}{*}{$\begin{array}{l}\text { Approximate } \\
\text { assignment }^{\mathrm{b}}\end{array}$} \\
\hline$\nu / \mathrm{cm}^{-1}$ & $I / \mathrm{km} \mathrm{mol}^{-1}$ & $\nu / \mathrm{cm}^{-1}$ & $\mathrm{I}^{\mathrm{c}}$ & \\
\hline 3167 & 5.4 & 3092 & $\mathrm{w}$ & $\nu \mathrm{C}-\mathrm{H}_{6 \mathrm{R}}$ \\
\hline 3164 & 2.2 & 3078 & $\mathrm{w}$ & $\nu \mathrm{C}-\mathrm{H}_{6 \mathrm{R}}$ \\
\hline 3152 & 4.6 & 3060 & $\mathrm{w}$ & $\nu \mathrm{C}-\mathrm{H}_{6 \mathrm{R}}$ \\
\hline 3139 & 1.2 & 3044 & $\mathrm{w}$ & $\nu \mathrm{C}-\mathrm{H}_{6 \mathrm{R}}$ \\
\hline 3127 & 10.3 & $3028 / 3020$ & $\mathrm{w} / \mathrm{sh}$ & $\nu \mathrm{C}-\mathrm{H}_{\mathrm{M}}$ \\
\hline 3095 & 8.9 & $3008 / 2994$ & $w / w$ & $\nu \mathrm{C}-\mathrm{H}_{\mathrm{M}}$ \\
\hline 3019 & 24.8 & 2958 & $\mathrm{w}$ & $\nu \mathrm{C}-\mathrm{H}_{\mathrm{M}}$ \\
\hline 1634 & 150.4 & 1619 & $\mathrm{~S}$ & $\nu \mathrm{C}=\mathrm{N}, \nu \mathrm{C}-\mathrm{C}_{6 \mathrm{R}}$ \\
\hline 1610 & 3.6 & 1591 & $\mathrm{w}$ & $\nu \mathrm{C}-\mathrm{C}_{6 \mathrm{R}}$ \\
\hline 1583 & 164.7 & 1564 & $\mathrm{~S}$ & $\nu \mathrm{C}-\mathrm{C}_{6 \mathrm{R}}, \nu \mathrm{C}=\mathrm{N}$ \\
\hline 1478 & 11.1 & 1471 & w & $\delta \mathrm{C}-\mathrm{C}-\mathrm{H}_{6 \mathrm{R}}$ \\
\hline 1476 & 10.8 & & & $\delta_{\mathrm{M}}$ \\
\hline 1466 & 2.7 & 1454 & w & $\delta_{\mathrm{M}}$ \\
\hline 1465 & 11.3 & & & $\delta_{\mathrm{M}}$ \\
\hline 1457 & 33.6 & $1434 / 1425$ & $\mathrm{~m} / \mathrm{sh}$ & $\delta_{\mathrm{M}}$ \\
\hline 1371 & 340.8 & 1384 & $\mathrm{~S}$ & $\nu \mathrm{C}_{5 \mathrm{R}}-\mathrm{O}, \nu \mathrm{C}-\mathrm{C}_{5 \mathrm{R}}$ \\
\hline 1355 & 210.6 & 1323 & $\mathrm{~S}$ & $\nu \mathrm{S}=\mathrm{O}$ \\
\hline 1328 & 70.8 & 1314 & $\mathrm{sh}$ & $\nu \mathrm{C}-\mathrm{C}_{6 \mathrm{R}}$ \\
\hline 1284 & 1.5 & 1273 & $\mathrm{w}$ & $\delta \mathrm{C}-\mathrm{C}-\mathrm{H}_{6 \mathrm{R}}$ \\
\hline 1211 & 3.6 & 1202 & w & $\delta_{\mathrm{M}}$ \\
\hline 1177 & 270.7 & 1174 & $\mathrm{~S}$ & $\nu \mathrm{S}=\mathrm{O}$ \\
\hline 1172 & 52.9 & 1163 & $\mathrm{sh}$ & $\delta \mathrm{C}-\mathrm{C}-\mathrm{H}_{6 \mathrm{R}}$ \\
\hline 1160 & 0.9 & 1155 & $\mathrm{sh}$ & $\delta_{\mathrm{M}}$ \\
\hline 1150 & 25.1 & 1146 & $\mathrm{sh}$ & $\delta \mathrm{C}-\mathrm{C}-\mathrm{H}_{6 \mathrm{R}}, \nu \mathrm{C}-\mathrm{C}_{6 \mathrm{R}}$ \\
\hline 1129 & 0.2 & 1121 & $\mathrm{w}$ & $\delta \mathrm{C}-\mathrm{C}-\mathrm{H}_{6 \mathrm{R}}, \nu \mathrm{C}-\mathrm{C}_{6 \mathrm{R}}$ \\
\hline 1049 & 18.9 & 1053 & $\mathrm{~m}$ & $\delta \mathrm{C}-\mathrm{C}-\mathrm{C}_{6 \mathrm{R}}$ \\
\hline 1025 & 0.9 & 1015 & $\mathrm{w}$ & $\nu \mathrm{C}-\mathrm{C}_{6 \mathrm{R}}$ \\
\hline 1005 & 0.0 & 1000 & $\mathrm{w}$ & $\gamma_{6 \mathrm{R}}$ \\
\hline 972 & 29.1 & 954 & $\mathrm{~m}$ & $\nu \mathrm{C}_{\mathrm{M}}-\mathrm{O}$ \\
\hline 970 & 0.6 & & & $\gamma_{6 \mathrm{R}}, \gamma_{5 \mathrm{R}}$ \\
\hline 896 & 63.5 & 916 & $\mathrm{~m}$ & $\nu \mathrm{N}-\mathrm{S}, \delta \mathrm{X}-\mathrm{C}-\mathrm{O}$ \\
\hline 891 & 0.0 & 908 & $\mathrm{~m}$ & $\gamma_{6 \mathrm{R}}$ \\
\hline 787 & 13.6 & 784 & $\mathrm{~m}$ & $\gamma_{6 R}$ \\
\hline 762 & 41.3 & 771 & $\mathrm{~m}$ & $\delta \mathrm{C}-\mathrm{C}-\mathrm{C}_{6 \mathrm{R}}$ \\
\hline 754 & 32.3 & 754 & $\mathrm{~m}$ & $\gamma_{6 \mathrm{R}}, \tau_{6 \mathrm{R}}$ \\
\hline 700 & 10.2 & 702 & $\mathrm{~m}$ & $\delta \mathrm{C}-\mathrm{C}-\mathrm{C}_{6 \mathrm{R}}$ \\
\hline 672 & 20.8 & 669 & $\mathrm{~m}$ & $\tau_{6 \mathrm{R}}$ \\
\hline 617 & 39.4 & 621 & $\mathrm{~m}$ & $\begin{array}{l}\delta \mathrm{C}-\mathrm{C}-\mathrm{C}_{6 \mathrm{R}} \\
\delta \mathrm{X}-\mathrm{S}=\mathrm{O}\end{array}$ \\
\hline 588 & 90.0 & 597 & $\mathrm{~S}$ & $\begin{array}{l}\gamma \mathrm{C}-\mathrm{S}(=\mathrm{O})-\mathrm{N} \\
\delta \mathrm{C}-\mathrm{X}-\mathrm{X}_{5 \mathrm{R}}\end{array}$ \\
\hline 538 & 15.5 & 539 & $\mathrm{~m}$ & $\begin{array}{l}\gamma \mathrm{C}-\mathrm{S}(=\mathrm{O})-\mathrm{N} \\
\delta \mathrm{C}-\mathrm{X}-\mathrm{X}_{5 \mathrm{R}}, \tau_{6 \mathrm{R}}\end{array}$ \\
\hline 529 & 20.1 & 532 & $\mathrm{sh}$ & $\delta \mathrm{X}-\mathrm{S}=\mathrm{O}$ \\
\hline 501 & 7.5 & 505 & $\mathrm{~m}$ & $\delta \mathrm{C}-\mathrm{X}-\mathrm{X}_{5 \mathrm{R}}$ \\
\hline
\end{tabular}

${ }^{\mathrm{a}}$ Frequencies scaled uniformly by the factor of $0.987 .{ }^{18}$

b Notation used in this table follows that of Ref. 18; 6R and 5R refer to the six- and five-membered ring, respectively; M stands for methyl group; $\nu, \delta, \gamma$, and $\tau$ indicate stretching, bending, rocking, and torsion modes, respectively; $\mathrm{X}$ designates either a $\mathrm{C}, \mathrm{S}$ or $\mathrm{N}$ atom.

${ }^{\mathrm{c}}$ Experimental intensities are provided as qualitative: $\mathrm{S}$, strong; $\mathrm{m}$, medium; w, weak; sh, shoulder.

the resulting sample cooling to room temperature, its infrared spectrum became equal to that of crystalline MBIOD (Fig. 3a, red line), fully confirming the nature of the product of the observed thermal process of MBID. 


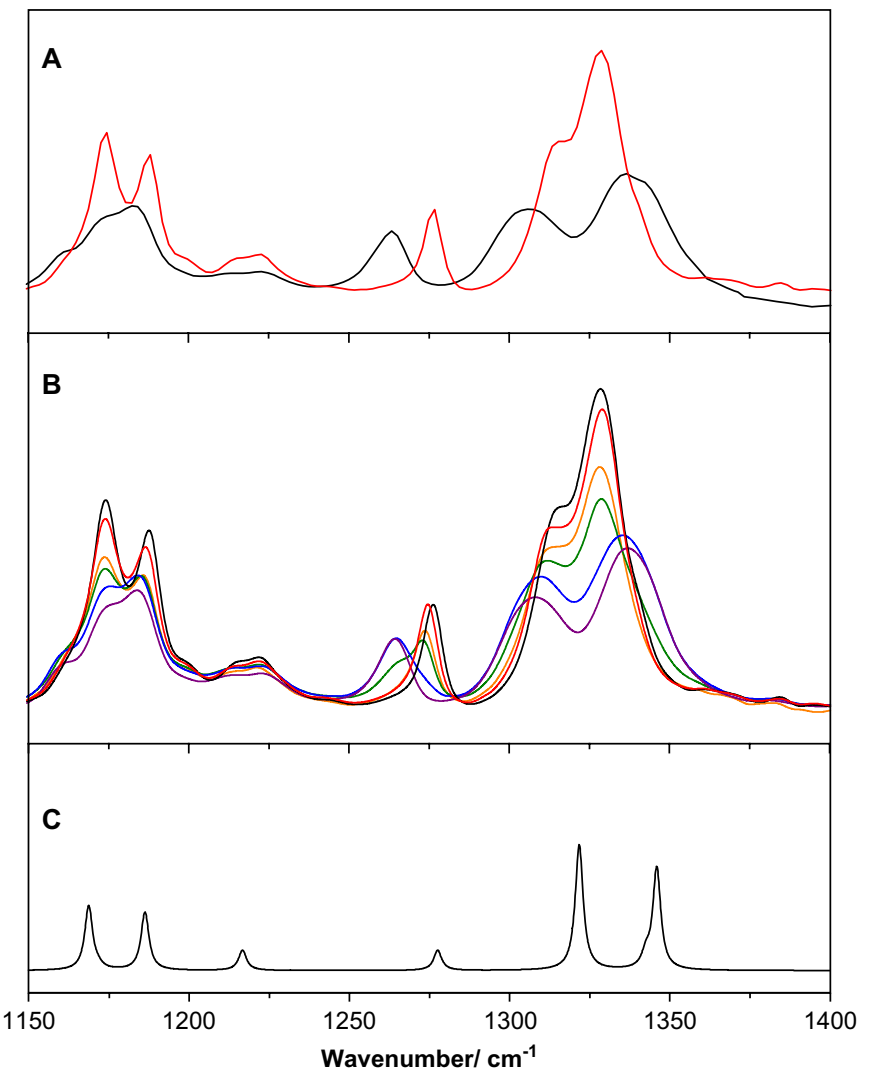

Figure 3. (a) Black trace: infrared spectrum obtained at the final of the heating process of the MBID sample (the same spectrum as in trace $f$ in Fig. 2); red trace: infrared spectrum of the same sample after letting the sample to cool to room temperature. (b) Black trace: infrared spectrum of the polycrystalline MBIOD sample ( $\mathrm{KBr}$ pellet) at room temperature $\left(20^{\circ} \mathrm{C}\right)$; color spectra: infrared spectra of the MBIOD sample subjected to heating (red: $90^{\circ} \mathrm{C}$, orange: $120^{\circ} \mathrm{C}$, green: $135^{\circ} \mathrm{C}$, blue: $138^{\circ} \mathrm{C}$, violet: $147^{\circ} \mathrm{C}$ ); in agreement with the known melting point of $\mathrm{MBIOD}\left(129^{\circ} \mathrm{C}\right)$, the spectral changes associated with melting of the compound can be clearly noticed by comparing the spectra obtained at 120 and $147^{\circ} \mathrm{C}$, whereas those obtained at intermediate temperatures indicate the ongoing melting process. (c) Calculated [DFT(B3LYP)/6$311++\mathrm{G}(3 \mathrm{df}, 3 \mathrm{pd})]$ infrared spectrum of MBIOD. (Displayed spectral range: $1150-1400 \mathrm{~cm}^{-1}$.)

Both the DSC and thermomicroscopy experiments, described in the following section, were also unequivocal proofs of MBIOD being the product of the observed thermal process of MBID, as it will be shown in detail below.

The spectra collected as a function of the temperature for the MBIOD sample (Fig. 3b) was also used, together with the DFT(B3LYP)/6-311++G(3df,3pd) calculated spectrum for this compound (Fig. 3c), to undertake the vibrational assignments for this species in both the crystalline and melted phases that are presented in Table 2. Like for MBID, the calculated spectrum for the isolated molecule fits nicely those obtained in the condensed phases, indicating that in this molecule intermolecular interactions are also weak enough to let the intramolecular modes almost unaffected. On the other hand, besides the usual band broadening associated with melting, the spectrum of the melted phase exhibits some relatively important frequency shifts when compared to that corresponding to the crystalline phase. The spectral range shown in
Figure 3 corresponds to the one where these changes are the most relevant. The most prominent band shift occurs for the band observed at $1276 \mathrm{~cm}^{-1}$ in the crystal spectrum, which moves to $1264 \mathrm{~cm}^{-1}$ in the spectrum of the melt. This band is ascribable to the all-in-phase in-plane bending of hydrogen atoms of the phenyl ring. The higher frequency observed for this mode in the spectrum of the crystal is then an indication of the steric restrictions imposed to the movement of the phenyl hydrogen atoms by the crystal environment. A significant shift to lower frequency upon melting is also observed for the band observed at $1316 \mathrm{~cm}^{-1}$, which has also a large contribution of the phenyl all-in-phase in-plane H-bending coordinate (see Table 2). On the contrary, the characteristic intensive band assigned to the $\nu \mathrm{S}=\mathrm{O}$ antisymmetric stretching mode shifts to higher frequency upon melting of the compound (from 1328 to $1337 \mathrm{~cm}^{-1}$ ), which can be correlated with a greater polarization of the $\mathrm{S}=\mathrm{O}$ bonds (i.e., larger contribution of the dipolar $\mathrm{S}^{+}-\mathrm{O}^{-}$structure) in the crystal. This interpretation is also supported by the considerable decrease of intensity experienced by this band upon melting (see Fig. 3b).

The infrared spectroscopic experiments carried out in this study also include kinetic studies on the observed Chapman rearrangement. In order to do this, diluted $\mathrm{KBr}$ pellets (MBID/ $\mathrm{KBr}$ ca. 1:100 in weight) were prepared, heated quickly to the desired temperature and then the consumption of the reactant followed by measuring the area under its characteristic and well isolated band at ca. $1619 \mathrm{~cm}^{-1}$. The results are summarized in Figure 4.

The results shown in Figure 4 clearly demonstrate that the Chapman reaction increases with the temperature and follows a sigmoidal kinetics. At the temperature of $190{ }^{\circ} \mathrm{C}$, i.e., slightly above the melting point of the reactant, the reaction is clearly faster, and in $10 \mathrm{~min}$ the amount of the reactant is below the detection limit of the experimental procedure used. When the sample was kept at a temperature below the melting point of the reactant but still close to it the rearrangement still occurred at a relatively fast rate. For example, at 180 and $170{ }^{\circ} \mathrm{C}$, the amount of unreacted MBID became smaller than the detection limit of the method in ca. 24 and $32 \mathrm{~min}$, respectively. However, for lower temperatures the process was found to slow down considerably: at $160{ }^{\circ} \mathrm{C}$ it took ca. $1 \mathrm{~h}$ and at $150{ }^{\circ} \mathrm{C}$ ca. $3 \mathrm{~h}$ to reduce the quantity of the reactant to below the experimental limit of detection. Hence, the first conclusion that can be extracted is that, contrarily to what was observed before by Dessolin and co-workers ${ }^{34,35}$ for 5methoxy-2-aryl-1,3,4-oxadiazoles, the Chapman rearrangement in MBID is faster in the melt than in the solid state. In addition, the sigmoid profile of the isotherms clearly reveals that the process is intermolecular in nature as suggested before for alkyl imidates. ${ }^{29}$

Bawn $^{44}$ has long ago proposed a kinetic model to consider processes where the reaction occurs both in solid and liquid states and where, as in the present case, the reactant is soluble in the product. This model predicts sigmoidal kinetic isotherms and has been used successfully many times in pharmaceutical sciences to explain decomposition of organic solids. Recently, the model was re-evaluated by Brown and Glass. ${ }^{45}$ 
Table 2

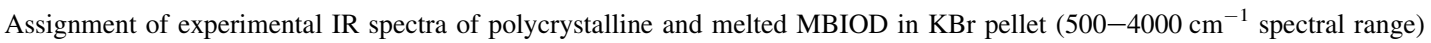

\begin{tabular}{|c|c|c|c|c|c|c|}
\hline \multirow{2}{*}{\multicolumn{2}{|c|}{ Calculated $^{\mathrm{a}}$ B3LYP/6-311++G(3df,3pd) }} & \multicolumn{4}{|c|}{ Experimental } & \multirow[t]{3}{*}{$\overline{\text { Approximate assignment }}{ }^{\mathrm{b}}$} \\
\hline & & \multicolumn{2}{|c|}{ Polycrystalline } & \multicolumn{2}{|l|}{ Melt } & \\
\hline$\nu / \mathrm{cm}^{-1}$ & $\mathrm{I} / \mathrm{km} \mathrm{mol}^{-1}$ & $\nu / \mathrm{cm}^{-1}$ & $\mathrm{I}^{\mathrm{c}}$ & $\nu / \mathrm{cm}^{-1}$ & $\mathrm{I}^{\mathrm{c}}$ & \\
\hline 3169 & 5.4 & 3095 & $\mathrm{~m}$ & 3095 & w & $\nu \mathrm{C}-\mathrm{H}_{6 \mathrm{R}}$ \\
\hline 3166 & 0.4 & 3084 & sh & 3084 & w & $\nu \mathrm{C}-\mathrm{H}_{6 \mathrm{R}}$ \\
\hline 3154 & 3.5 & 3072 & w & 3074 & $\mathrm{w}$ & $\nu \mathrm{C}-\mathrm{H}_{6 \mathrm{R}}$ \\
\hline 3141 & 1.5 & 3035 & w & 3030 & $\mathrm{w}$ & $\nu \mathrm{C}-\mathrm{H}_{6 \mathrm{R}}$ \\
\hline 3106 & 0.1 & 3016 & w & & & $\nu \mathrm{C}-\mathrm{H}_{\mathrm{M}}$ \\
\hline 3073 & 7.1 & 2952 & w & 2950 & $\mathrm{w}$ & $\nu \mathrm{C}-\mathrm{H}_{\mathrm{M}}$ \\
\hline 3008 & 28.6 & 2925 & $\mathrm{w}$ & 2925 & sh & $\nu \mathrm{C}-\mathrm{H}_{\mathrm{M}}$ \\
\hline 1757 & 367.4 & 1739 & $\mathrm{~S}$ & 1737 & $\mathrm{~S}$ & $\nu \mathrm{C}=\mathrm{O}$ \\
\hline 1612 & 5.1 & 1595 & w & 1593 & w & $\nu \mathrm{C}-\mathrm{C}_{6 \mathrm{R}}$ \\
\hline 1606 & 5.3 & & & & & $\nu \mathrm{C}-\mathrm{C}_{6 \mathrm{R}}$ \\
\hline 1494 & 18.0 & 1469 & $\mathrm{~m}$ & 1464 & $\mathrm{~m}$ & $\delta_{\mathrm{M}}$ \\
\hline 1477 & 6.6 & 1460 & $\mathrm{~m}$ & 1456 & $\mathrm{sh}$ & $\delta \mathrm{C}-\mathrm{C}-\mathrm{H}_{6 \mathrm{R}}$ \\
\hline 1474 & 6.7 & & & & & $\delta_{\mathrm{M}}$ \\
\hline 1469 & 8.3 & & & & & $\delta \mathrm{C}-\mathrm{C}-\mathrm{H}_{6 \mathrm{R}}$ \\
\hline 1431 & 21.2 & 1422 & $\mathrm{~m}$ & $1422 / 1417$ & $\mathrm{w} / \mathrm{sh}$ & $\delta_{\mathrm{M}}$ \\
\hline 1346 & 208.0 & 1328 & $\mathrm{~S}$ & 1337 & $\mathrm{~S}$ & $\nu \mathrm{S}=\mathrm{O}$ \\
\hline 1343 & 28.4 & & & & & $\nu \mathrm{C}-\mathrm{C}_{6 \mathrm{R}}$ \\
\hline 1322 & 257.2 & 1315 & $\mathrm{~S}$ & 1308 & $\mathrm{~S}$ & $\nu \mathrm{C}_{9}-\mathrm{N}, \nu \mathrm{C}_{17}-\mathrm{N}$ \\
\hline 1278 & 41.5 & 1276 & $\mathrm{~m}$ & 1264 & $\mathrm{~m}$ & $\delta \mathrm{C}-\mathrm{C}-\mathrm{H}_{6 \mathrm{R}}$ \\
\hline 1217 & 41.5 & $1221 / 1214$ & $\mathrm{~m} / \mathrm{sh}$ & $1223 / 1213$ & $\mathrm{~m} / \mathrm{sh}$ & $\delta_{\mathrm{M}}, \nu \mathrm{C}-\mathrm{C}_{5 \mathrm{R}}$ \\
\hline 1186 & 118.7 & 1187 & $\mathrm{~S}$ & 1183 & $\mathrm{~S}$ & $\nu \mathrm{S}=\mathrm{O}$ \\
\hline 1172 & 5.4 & $1174 / 1160$ & $\mathrm{~S} / \mathrm{sh}$ & $1176 / 1162$ & $\mathrm{sh} / \mathrm{sh}$ & $\delta \mathrm{C}-\mathrm{C}-\mathrm{H}_{6 \mathrm{R}}$ \\
\hline 1169 & 131.8 & & & & & $\nu \mathrm{S}=\mathrm{O}$ \\
\hline 1142 & 0.6 & 1132 & $\operatorname{sh}$ & 1137 & $\operatorname{sh}$ & $\delta_{\mathrm{M}}$ \\
\hline 1129 & 7.3 & 1127 & w & 1125 & $\mathrm{w}$ & $\delta \mathrm{C}-\mathrm{C}-\mathrm{H}_{6 \mathrm{R}}, \nu \mathrm{C}-\mathrm{C}_{6 \mathrm{R}}$ \\
\hline 1058 & 15.7 & 1057 & $\mathrm{~m}$ & 1059 & $\mathrm{~m}$ & $\delta \mathrm{C}-\mathrm{C}-\mathrm{C}_{6 \mathrm{R}}$ \\
\hline 1028 & 0.8 & 1022 & $\mathrm{w}$ & 1019 & $\mathrm{w}$ & $\nu \mathrm{C}-\mathrm{C}_{6 \mathrm{R}}$ \\
\hline 1009 & 0.0 & 999 & $\mathrm{w}$ & 999 & $\mathrm{w}$ & $\gamma_{6 \mathrm{R}}$ \\
\hline 976 & 0.6 & 978 & $\mathrm{~m}$ & 971 & $\mathrm{~m}$ & $\gamma_{6 \mathrm{R}}$ \\
\hline 970 & 65.7 & 968 & sh & 960 & sh & $\nu \mathrm{C}_{17}-\mathrm{N}, \nu \mathrm{C}_{9}-\mathrm{N}$ \\
\hline 896 & 0.1 & not obsd & - & not obsd & - & $\gamma_{6 \mathrm{R}}$ \\
\hline 879 & 31.4 & 890 & $\mathrm{~m}$ & 882 & $\mathrm{~m}$ & $\nu \mathrm{N}-\mathrm{S}, \delta_{\mathrm{M}}, \delta \mathrm{X}-\mathrm{C}=\mathrm{O}$ \\
\hline 793 & 9.5 & 785 & w & 787 & $\mathrm{w}$ & $\gamma \mathrm{C}-\mathrm{C}(=\mathrm{O})-\mathrm{N}, \gamma_{6 \mathrm{R}}$ \\
\hline 757 & 36.3 & 751 & $\mathrm{~S}$ & 749 & $\mathrm{~S}$ & $\tau_{6 \mathrm{R}}, \gamma_{6 \mathrm{R}}$ \\
\hline 743 & 18.6 & & & & & $\delta \mathrm{C}-\mathrm{C}-\mathrm{C}_{6 \mathrm{R}}$ \\
\hline 686 & 4.3 & 685 & $\mathrm{~m}$ & 685 & $\mathrm{w}$ & $\delta \mathrm{C}-\mathrm{C}-\mathrm{C}_{6 \mathrm{R}}$ \\
\hline 676 & 20.8 & 675 & $\mathrm{~m}$ & 675 & $\mathrm{~m}$ & $\tau_{6 \mathrm{R}}$ \\
\hline 606 & 31.5 & 609 & $\mathrm{~m}$ & 610 & $\mathrm{~m}$ & $\delta \mathrm{X}-\mathrm{S}=\mathrm{O}, \delta \mathrm{X}-\mathrm{C}=\mathrm{O}$ \\
\hline 579 & 62.7 & 591 & $\mathrm{~S}$ & 587 & $\mathrm{~S}$ & $\gamma \mathrm{C}-\mathrm{S}(=\mathrm{O})-\mathrm{N}$ \\
\hline 533 & 14.8 & 528 & $\mathrm{~m}$ & 532 & $\mathrm{~m}$ & $\gamma \mathrm{C}-\mathrm{S}(=\mathrm{O})-\mathrm{N}, \tau_{6 \mathrm{R}}$ \\
\hline 505 & 25.6 & 512 & $\mathrm{~m}$ & 508 & $\mathrm{~m}$ & $\delta \mathrm{C}-\mathrm{X}-\mathrm{X}_{5 \mathrm{R}}$ \\
\hline
\end{tabular}

${ }^{\text {a }}$ Frequencies scaled uniformly by the factor of $0.987 .{ }^{18}$

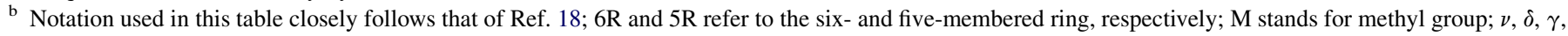
and $\tau$ indicate stretching, bending, rocking, and torsion modes, respectively; $\mathrm{X}$ designates either a $\mathrm{C}, \mathrm{S}$ or $\mathrm{N}$ atom.

c Experimental intensities are provided as qualitative: S, strong; m, medium; w, weak; sh, shoulder.

The Bawn kinetical parameters obtained for the studied process at different temperatures are summarized in Table 3 . The ordinate of the inflexion point in the isothermal curves shown in Figure 4, which allows obtaining the Bawn's solubility parameter ( $s$; see Table 3 ), is about $0.5-0.6$ for all the isotherms (i.e., the $\alpha^{*}$ parameter in the Bawn model is within the $0.4-0.5$ range), which is a result compatible with the adequacy of the Bawn model to the description of the system under study. ${ }^{45}$ The most important kinetical parameter extracted from the Bawn model is the ratio between the rate coefficients for reactions in the solid $\left(k_{\mathrm{s}}\right)$ and liquid phases $\left(k_{1}\right)$. In the present case, for the highest temperatures investigated, besides the product of reaction, the reactant is also partially melted and the ratio of the effective rate coefficients is high. Note that both the formation of the product and the presence of the ionic matrix media contribute to reduce the melting point of the reactant, which explains the fact that the reactions at temperatures slightly below the melting point of the pristine reactant (ca. $184^{\circ} \mathrm{C}$ ) are still considerably fast. On the other hand, for the lowest temperatures investigated, the reaction in the liquid phase is strongly limited by the availability of the product resulting from the initial reaction in the solid phase (MBIOD melting point is ca. $129^{\circ} \mathrm{C}$, so this happens for all temperatures considered); accordingly, the $k_{1} / k_{\mathrm{s}}$ ratio becomes much smaller. 


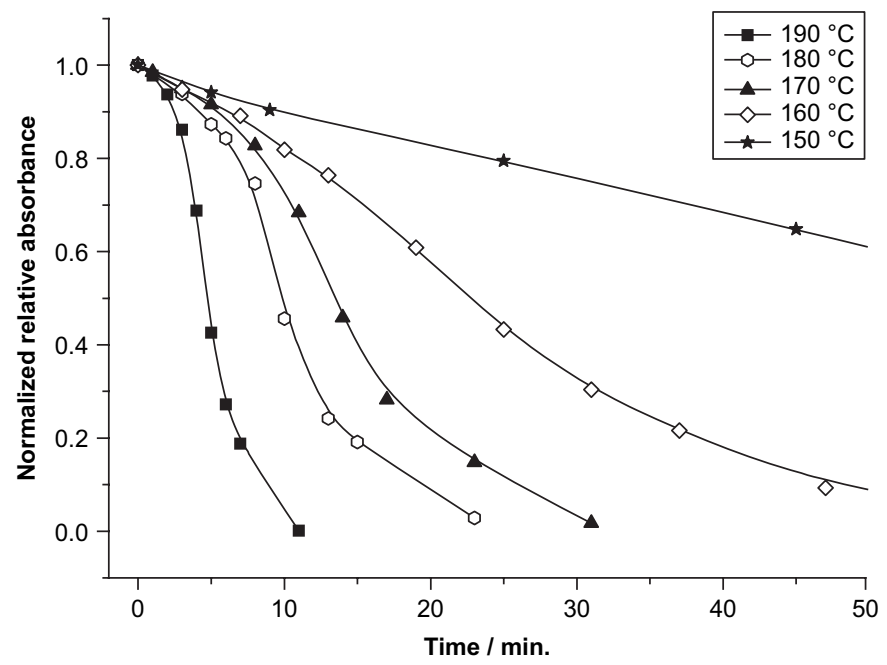

Figure 4. Plot of the integrated absorbance of the MBID band at ca. $1619 \mathrm{~cm}^{-1}$ as a function of time, for various temperatures. The absorbances of the spectra registered at $t=0 \mathrm{~min}$ at each temperature considered were normalized to unity. Initial concentrations of the reactant species in the $\mathrm{KBr}$ pellet are equal (all $\mathrm{KBr}$ pellets were prepared from the same $\mathrm{MBID} / \mathrm{KBr}$ mixture, with a weight ratio of $1: 100)$

Table 3

Kinetic parameters obtained from the Bawn model for the isotherms shown in Figure 4

\begin{tabular}{lrlllllr}
\hline$T /{ }^{\circ} \mathrm{C}$ & \multicolumn{1}{l}{$t^{*}$} & $1-\alpha^{*}$ & $\alpha^{*}$ & $s$ & $k_{1}$ & $k_{\mathrm{s}}$ & \multicolumn{1}{c}{$k_{1} / k_{\mathrm{s}}$} \\
\hline 190 & 4.44 & 0.58 & 0.42 & 1.39 & 0.484 & 0.017 & 28.44 \\
180 & 9.40 & 0.54 & 0.46 & 1.18 & 0.207 & 0.014 & 14.81 \\
170 & 12.72 & 0.55 & 0.45 & 1.23 & 0.146 & 0.011 & 13.15 \\
160 & 20.85 & 0.55 & 0.45 & 1.22 & 0.062 & 0.013 & 4.72 \\
150 & 52.78 & 0.59 & 0.41 & 1.43 & 0.016 & 0.007 & 2.29
\end{tabular}

$t^{*}$ is the time corresponding to the inflection point of the isotherms shown in Figure 4, whose ordinate is $1-\alpha^{*} . s=\left(1-\alpha^{*}\right) / \alpha^{*}$ is the Bawn solubility parameter. $k_{1}$ and $k_{2}$ are the rate coefficients for the liquid and solid state reaction phases reaction, respectively, and were obtained, accordingly to the Bawn model, by non-linear fitting of the following two equations to the kinetical data $[(1-\alpha)=f(t)]:(1-\alpha)=\left(1-\alpha^{*}\right) \exp \left[-k_{1}\left(t-t^{*}\right)\right]$, for $0<t<t^{*}$, to obtain $k_{1}$; $(1-\alpha)=1-k_{\mathrm{s}} /\left(s k_{1}-s k_{\mathrm{s}}-k_{\mathrm{s}}\right)\left\{\exp \left[\left(s k_{1}-s k_{\mathrm{s}}-k_{\mathrm{s}}\right) t\right]-1\right\}$, for $t>t^{*}$, to obtain $k_{\mathrm{s}}$.

\subsection{DSC and polarized light thermomicroscopy experiments}

The thermal behavior of pure MBIOD was characterized by differential scanning calorimetry between 25 and $210{ }^{\circ} \mathrm{C}$ and a typical heating run thermogram is shown in Figure 5a. A single peak is observed, corresponding to the melting process, which occurs at $T_{\text {fus }}=129.3 \pm 0.2{ }^{\circ} \mathrm{C}(n=4)$. The corresponding enthalpy, $\Delta H_{\text {fus }}$ is $19.5 \pm 0.3 \mathrm{~kJ} \mathrm{~mol}^{-1}(n=4)$. Images obtained by thermomicroscopy for the phase transition observed in pure MBIOD are shown in Figure 6a, where the starting of the fusion can be clearly noticed in the image obtained at $129.3{ }^{\circ} \mathrm{C}$. Below this temperature no changes in the sample were observed.

MBID samples were studied in the same temperature range and a characteristic first heating thermogram is shown in Figure 5b. A low enthalpic endothermic transition $\left[\Delta H_{\mathrm{trs}}=1.6 \pm\right.$ $\left.0.3 \mathrm{~kJ} \mathrm{~mol}^{-1}(n=5)\right]$ is observed at $T_{\mathrm{trs}}=120.3 \pm 0.2^{\circ} \mathrm{C}(n=5)$ and the melting process occurs at $T_{\text {fus }}=183.7 \pm 0.2{ }^{\circ} \mathrm{C}(n=5)$.

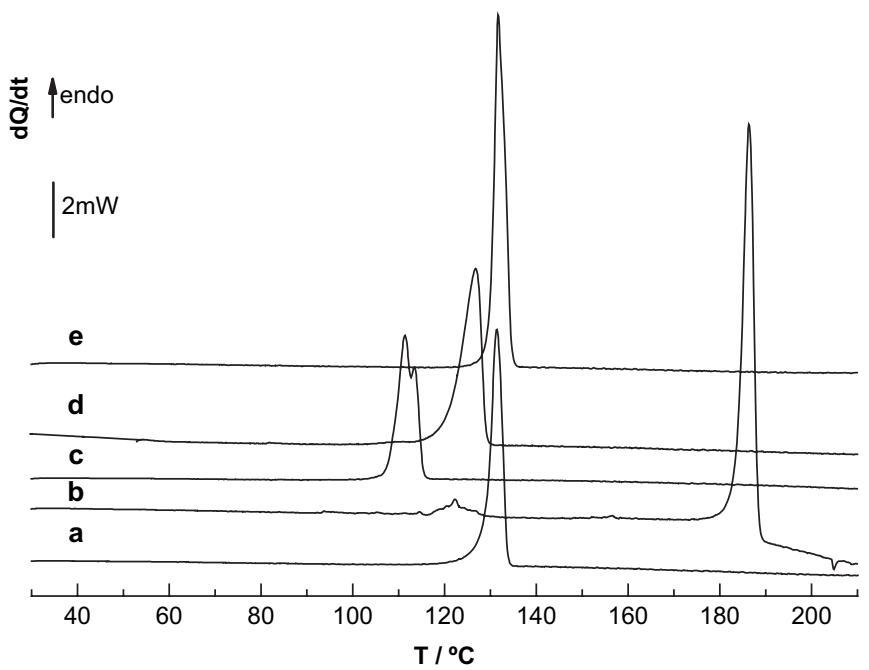

Figure 5. DSC heating curves: (a) MBIOD ( $m=1.83 \mathrm{mg})$; (b) MBID ( $m=2.26 \mathrm{mg}$ ) 1st heating scan; (c) the liquid obtained in the first heating scan of a MBID ( $m=1.59 \mathrm{mg}$ ) sample was immediately cooled to $25^{\circ} \mathrm{C}$. Thermogram (c) reports the subsequent heating scan; (d) the melt obtained in (b) was kept for $15 \mathrm{~min}$ at $210^{\circ} \mathrm{C}$ and then cooled to $25^{\circ} \mathrm{C}$. Thermogram (d) was obtained in the subsequent heating run; (e) the liquid obtained in (d) stayed at $210^{\circ} \mathrm{C}$ for $30 \mathrm{~min}$ before the cooling process. Thermogram (e) was registered in the subsequent heating scan. All scanning steps were performed at $10{ }^{\circ} \mathrm{C} \mathrm{min}^{-1}$.

The large baseline change that is observed between the beginning and the end of the melting peak is indicative of thermal conversion of the starting compound. The thermomicroscopy study (Fig. 6b and movie provided as Supplementary data), allowed to recognize the first transition as a solid/solid one (not detectable by IR), and to confirm that, under the used experimental conditions, no other modifications occur until fusion, that is, to say MBID is stable in the solid state, when heated at $10{ }^{\circ} \mathrm{C} \min ^{-1}$.

The cooling experiments, performed at $10^{\circ} \mathrm{C} \mathrm{min}^{-1}$, gave rise to crystallization of the liquid at temperatures between 80 and $65^{\circ} \mathrm{C}$, and no conclusions can be drawn from the obtained curves. On the other hand, the thermogram profiles obtained in the heating runs performed after cooling the liquid from 210 to $25^{\circ} \mathrm{C}$ were found to be particularly informative. They depend on the time the liquid was left at the higher temperature and, therefore, on the extent of MBID to MBIOD conversion: if the liquid is cooled at once, the result shown in Figure 5c is obtained; annealing for $15 \mathrm{~min}$ or for 15 plus additional $30 \mathrm{~min}$ at $210^{\circ} \mathrm{C}$ give rise to the thermograms presented in Figure 5d and e, respectively. Thermomicroscopy images obtained in the conditions of Figure $5 \mathrm{c}$ and e are presented in Figure $6 \mathrm{c}$ and $d$, correspondingly. In Figure 5e a narrow peak is observed, as expected when a pure substance melts, and the peak onset temperature and transition enthalpy match those obtained for MBIOD fusion process, clearly testifying conversion of MBID into this compound. A $15+$ $30 \mathrm{~min}$ annealing at $210^{\circ} \mathrm{C}$ allows the complete conversion of MBID into MBIOD, while the other thermal treatments lead to incomplete conversion, resulting in the lowering of MBIOD melting point. 
(a)

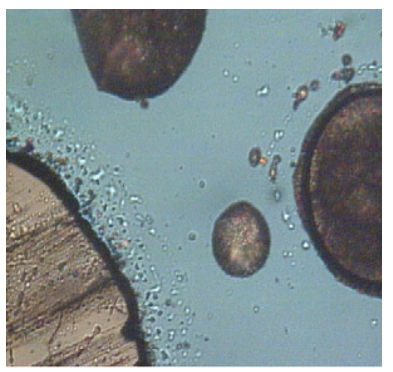

$25^{\circ} \mathrm{C}$

(b)

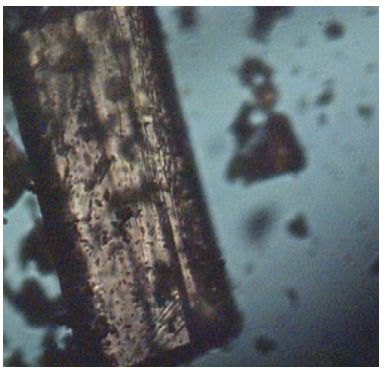

$25^{\circ} \mathrm{C}$

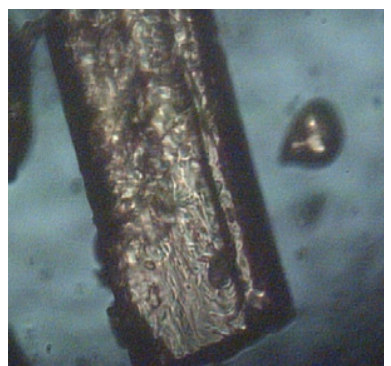

$182.3^{\circ} \mathrm{C}$

(c)

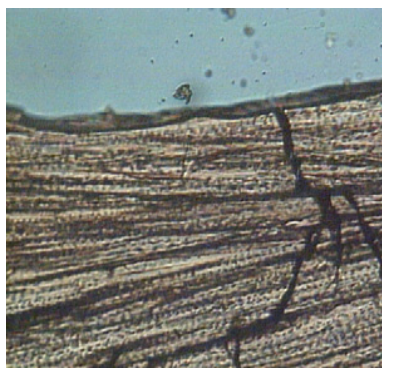

$25^{\circ} \mathrm{C}$

(d)

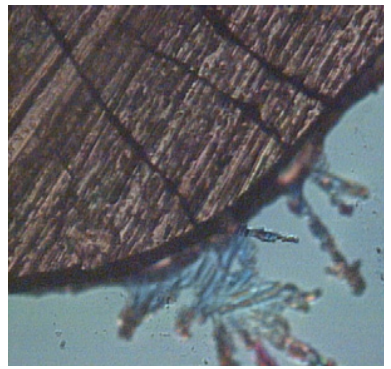

$25^{\circ} \mathrm{C}$

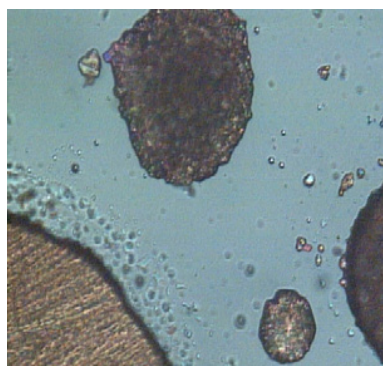

$129.3^{\circ} \mathrm{C}$

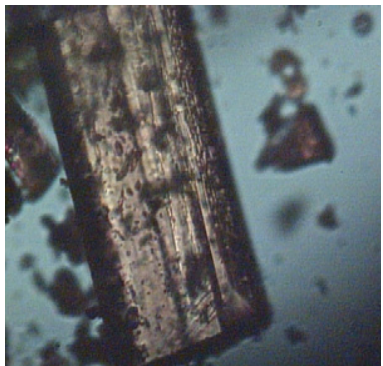

$118.1^{\circ} \mathrm{C}$

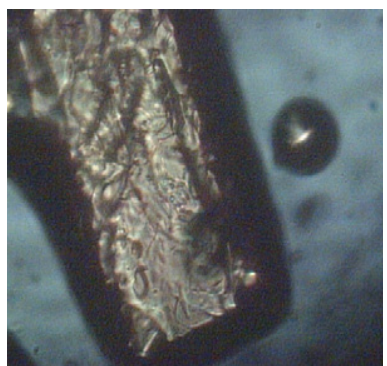

$184.1^{\circ} \mathrm{C}$

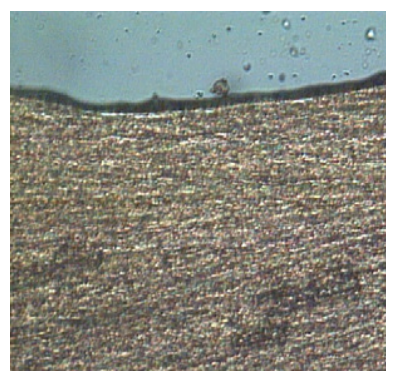

$110.5^{\circ} \mathrm{C}$

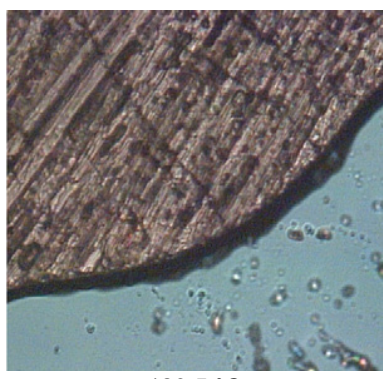

$129.5^{\circ} \mathrm{C}$

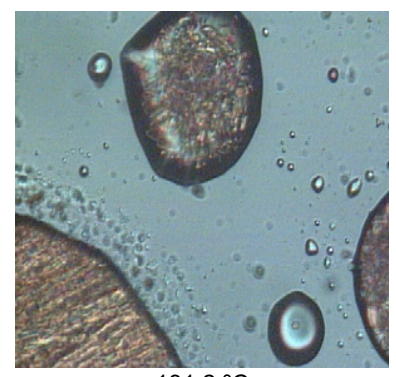

$131.2^{\circ} \mathrm{C}$

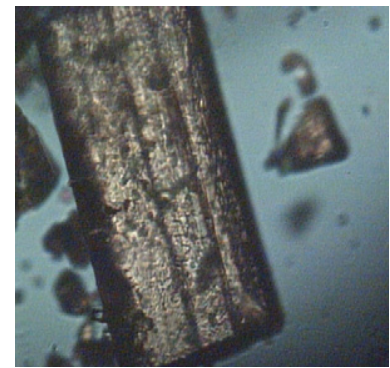

$123.2^{\circ} \mathrm{C}$

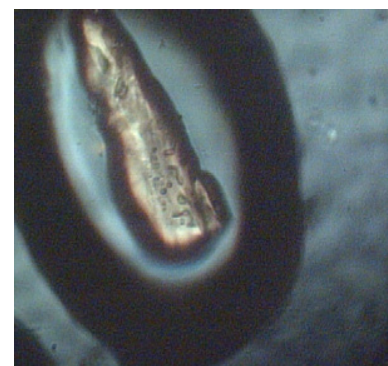

$185.5^{\circ} \mathrm{C}$

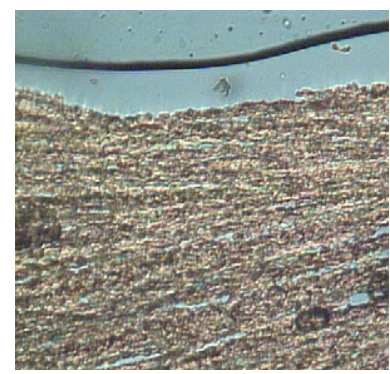

$111.9^{\circ} \mathrm{C}$

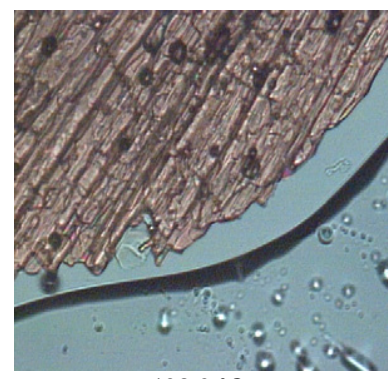

$132.0^{\circ} \mathrm{C}$

Figure 6. Phase transitions observed by thermomicroscopy: (a) MBIOD fusion. (b) MBID 1st heating scan: solid/solid transition and melting. (c) The liquid obtained in a MBID first heating run was immediately cooled to $25^{\circ} \mathrm{C}$. The images report the subsequent heating scan. (d) Images for a heating process of a MBID sample treated as in Figure 5e. All scanning steps performed at $10^{\circ} \mathrm{C} \mathrm{min}^{-1}$. 
In the preceding experiments conversion of MBID to MBIOD by annealing of the melt at $210{ }^{\circ} \mathrm{C}$ was achieved. An additional DSC experiment was also made, in order to further confirm, by an independent method, the likelihood of the isomerization in the solid state. In this experiment, a MBID sample was heated until $160{ }^{\circ} \mathrm{C}$ at $10{ }^{\circ} \mathrm{C} \mathrm{min}^{-1}$ and left at that temperature for $3 \mathrm{~h}$. The sample was then rapidly cooled to room temperature and reheated to $210{ }^{\circ} \mathrm{C}$. As expected, the thermogram corresponding to this latter heating run was found to closely match that presented in Figure $5 \mathrm{c}$, indicating that partial conversion of MBID to MBIOD took place.

A final note concerning the kinetics of the process must be considered here, since apparently the DSC experiments do not fit exactly the kinetical results as determined by infrared spectroscopy in what concerns the time required to complete the rearrangement reaction, which appear to be longer by the former methods. In spite of the fact that the experimental conditions in the two experiments were not exactly the same and this might have influenced somewhat the results (in the infrared experiments the size of the MBID crystals was reduced before use-during preparation of the $\mathrm{KBr}$ pellets-thus increasing the accessible area of the reactant and eventually led to increase the reaction rate), the main cause for this apparent discrepancy is certainly a result of the lower sensibility of the infrared experiments to detect trace amounts of unreacted MBID when compared to DSC. Indeed, in the DSC experiments, the presence of such low amounts produces an easily noticeable decrease in the melting point of MBIOD, which is then a highly sensitive indirect way to detect trace amounts of unreacted MBID in the sample after thermal treatment. On the other hand, in the infrared experiments the amount of MBID had to be estimated from band intensity measurements, which necessarily implies a higher detection limit, since the bands are relatively broad and, for very low intensities, they might easily be concealed within the baseline.

\section{Conclusion}

The Chapman isomerization of the pseudosaccharyl ether, 3-(methoxy)-1,2-benzisothiazole 1,1-dioxide (MBID) to the corresponding $N$-methyl pseudosaccharin (MBIOD) was studied by infrared spectroscopy, DSC, and thermomicroscopy. It was shown that, besides taking place at temperatures above the melting point of the reactant $\left(\mathrm{ca} .184^{\circ} \mathrm{C}\right.$ ) this reaction does also occur in the solid state, at temperatures as low as $150{ }^{\circ} \mathrm{C}$. To the best of our knowledge this was the first observation of a Chapman-like $\left[1,3^{\prime}\right]$-isomerization in pseudosaccharin ethers in the solid state. The reaction was found to obey a Bawn-type kinetics, showing sigmoid isotherms, with the $k_{1} / k_{\mathrm{s}}$ ratio decreasing with temperature and the Bawn's $\alpha^{*}$ parameter in the $0.4-0.5$ range for all temperatures investigated.

The phase changes in both compounds were also investigated: MBID was found to have a solid/solid transition at $120.3 \pm 0.2 \mathrm{~K}\left(\Delta H=1.6 \pm 0.3 \mathrm{~kJ} \mathrm{~mol}^{-1}\right)$ and fusion at $183.7 \pm$ $0.2{ }^{\circ} \mathrm{C}$; MBIOD shows a single phase transition within the temperature range investigated, corresponding to melting, which occurs at $129.3 \pm 0.2{ }^{\circ} \mathrm{C} \quad\left(\Delta H=19.5 \pm 0.3 \mathrm{~kJ} \mathrm{~mol}^{-1}\right)$. The infrared spectrum of crystalline MBID and those of MBIOD in both crystalline and liquid phases were fully assigned on the basis of comparison with results of theoretical calculations and, for MBID, also taking into account previous experimental data obtained for the compound isolated in cryogenic inert matrices. ${ }^{18}$

\section{Acknowledgements}

The research was supported by the Portuguese Fundação para a Ciência e a Tecnologia (Grant FCT \#SFRH/BPD/ 17081/2004 and projects POCI/QUI/59019/2004 and POCI/ QUI/58937/2004) and Instituto de Investigação Interdisciplinar, Universidade de Coimbra, Portugal III/BIO/40/2005. Calculations were partially done at the Academic Computer Center 'Cyfronet', Krakow, Poland (Grant KBN/SGI_ORIGIN_2000/UJ/044/1999), which is acknowledged for computing time. A.G.Z. is member of the research career Conicet (National Research Council, Argentina).

\section{Supplementary data}

It consists of (a) ${ }^{1} \mathrm{NMR}$ and mass spectra for MBID and MBIOD, and (b) movie with the changes in the MBID sample in the solid/solid phase transition region $\left(110-130^{\circ} \mathrm{C}\right)$ as observed in the thermomicroscopy experiments. Supplementary data associated with this article can be found in the online version, at doi:10.1016/j.tet.2008.02.007.

\section{References and notes}

1. Wepplo, P. J.; Rampulla, R. A.; Heffernan, G. D.; Cosette, M. V.; Langevine, C. M.; Kameswaran, V.; Diehl, R. E.; Guaciaro, M. A. EP1274708, 2003.

2. Otten, M.; von Deyn, W.; Engel, S.; Hill, R. L.; Kardorff, U.; Vossen, M.; Plath, P.; Walter, H. EP0961774, 1999.

3. Zani, F.; Mingiardi, M. R.; Maggiali, C. A.; Mazza, P. Farmaco 1996, 51 , 707.

4. Mor, M.; Zani, F.; Mazza, P.; Silva, C.; Bordi, F.; Morini, G.; Plazzi, P. V. Farmaco 1996, 51, 493.

5. Zani, F.; Vicini, P. Arch. Pharm. Pharm. Med. Chem. 1998, 331, 219.

6. Eacho, P. I.; Foxworthy-Mason, P. S.; Lin, H.-S.; Lopez, J. E.; Mosior, M. K.; Richett, M. E. EP1274708, 2006.

7. Marco, J. L.; Ingate, S. T.; Jaime, C.; Bea, J. Tetrahedron 2000, 56, 2523

8. Ahn, K. H.; Baek, H. H.; Lee, S. J.; Cho, C. W. J. Org. Chem. 2000, 65, 7690.

9. Powers, J. C.; Asgian, J. L.; Ekici, O. D.; James, K. E. Chem. Rev. 2002 102,4639

10. Brigas, A. F.; Johnstone, R. A. W. Tetrahedron Lett. 1990, 31, 5789.

11. Araújo, N. C. P.; Brigas, A. F.; Cristiano, M. L. S.; Frija, L. M. T.; Guimarães, E. M. O.; Loureiro, R. M. S. J. Mol. Catal. A 2004, 215, 113.

12. Frija, L. M. T.; Cristiano, M. L. S.; Guimarães, E. M. O.; Martins, N. C.; Loureiro, R. M. S.; Bickley, J. J. Mol. Catal. A 2005, 242, 241.

13. Brigas, A. F.; Johnstone, R. A. W. J. Chem. Soc., Chem. Commun. 1994, 1923.

14. Brigas, A. F.; Johnstone, R. A. W. J. Chem. Soc., Perkin Trans. 12000 , 1735 .

15. Alves, J. A. C.; Barkley, J. V.; Brigas, A. F.; Johnstone, R. A. W. J. Chem Soc., Perkin Trans. 2 1997, 669. 
16. Barkley, J. V.; Cristiano, M. L. S.; Johnstone, R. A. W.; Loureiro, R. M. S. Acta Crystallogr. 1997, C53, 383.

17. Araujo, N. C. P.; Barroca, P. M. M.; Bickley, J. F.; Brigas, A. F.; Cristiano, M. L. S.; Johnstone, R. A. W.; Loureiro, R. M. S.; Pena, P. C. A. J. Chem. Soc., Perkin Trans. 1 2002, 1213.

18. Kaczor, A.; Almeida, R.; Gómez-Zavaglia, A.; Cristiano, M. L. S.; Fausto, R. J. Mol. Struct., in press. doi:10.1016/j.molstruc.2007.06.004

19. Chapman, A. W. J. Chem Soc. 1925, 127, 1992.

20. Mumm, O.; Hesse, H.; Volquartz, H. Chem. Ber. 1915, 48, 397.

21. March, A.; Nolen, E. G.; Gardiner, K. M.; Lehn, J. M. Tetrahedron Lett. 1994, 35, 397.

22. Kuroda, T.; Suzuki, F. Tetrahedron Lett. 1992, 33, 2027.

23. Farouz, F.; Miller, M. J. Tetrahedron Lett. 1991, 32, 3305.

24. Schulenberg, J. W.; Archer, S. Org. React. 1965, 14, 1.

25. Burdukovskii, V. F.; Mognonov, D. M.; Allayarov, S. R.; Botoeva, S. O.; Mazurevskaya, Zh P. Russ. Chem. Bull. 2004, 53, 1773.

26. Wiberg, K. B.; Rowland, B. I. J. Am. Chem. Soc. 1955, 77, 2205.

27. Wheeler, O. G. J. Org. Chem. 1969, 34, 966.

28. Relles, H. M. J. Org. Chem. 1968, 33, 2245.

29. Challis, B. C.; Frenkel, A. D. J. Chem. Soc., Chem. Commun. 1972, 303.

30. Taylor, E. C. Acc. Chem. Res. 1972, 3, 1970.

31. Brawn, D. J.; Foster, R. V. J. Chem. Soc. 1965, 4911.

32. Plenkiewicz, J. Tetrahedron Lett. 1978, 4, 399.

33. Paolini, L.; Tosato, M. L.; Cignitti, M. J. Heterocycl. Chem. 1968, 5, 533.

34. Déssolin, M.; Eisenstein, O.; Golfier, M.; Plangé, T.; Sautet, P. J. Chem. Soc., Chem. Commun. 1992, 132.

35. Déssolin, M.; Golfier, M. J. Chem. Soc., Chem. Commun. 1986, 38.

36. Hettler, H. Tetrahedron Lett. 1968, 15, 1793.
37. Hettler, H.; Neygenfind, H. Tetrahedron Lett. 1966, 48, 6031.

38. Hettler, H. Tetrahedron Lett. 1968, 15, 1791.

39. Neygenfind, H.; Hettler, H. Tetrahedron Lett. 1968, 48, 5509.

40. Sabbah, R.; Wu, A. X.; Chickos, J. S.; Leitão, M. L. P.; Roux, M. V.; Torres, L. A. Thermochim. Acta 1995, 331, 93.

41. Becke, A. D. Phys. Rev. A 1988, 38, 3098.

42. Lee, C. T.; Yang, W. T.; Parr, R. G. Phys. Rev. B 1988, 37, 785-789.

43. Frisch, M. J.; Trucks, G. W.; Schlegel, H. B.; Scuseria, G. E.; Robb, M. A.; Cheeseman, J. R.; Montgomery, J. A., Jr.; Vreven, T.; Kudin, K. N.; Burant, J. C.; Millam, J. M.; Iyengar, S. S.; Tomasi, J.; Barone, V.; Mennucci, B.; Cossi, M.; Scalmani, G.; Rega, N.; Petersson, G. A.; Nakatsuji, H.; Hada, M.; Ehara, M.; Toyota, K.; Fukuda, R.; Hasegawa, J.; Ishida, M.; Nakajima, T.; Honda, Y.; Kitao, O.; Nakai, H.; Klene, M.; Li, X.; Knox, J. E.; Hratchian, H. P.; Cross, J. B.; Bakken, V.; Adamo, C.; Jaramillo, J.; Gomperts, R.; Stratmann, R. E.; Yazyev, O.; Austin, A. J.; Cammi, R.; Pomelli, C.; Ochterski, J. W.; Ayala, P. Y.; Morokuma, K.; Voth, G. A.; Salvador, P.; Dannenberg, J. J.; Zakrzewski, V. G.; Dapprich, S.; Daniels, A. D.; Strain, M. C.; Farkas, O.; Malick, D. K.; Rabuck, A. D.; Raghavachari, K.; Foresman, J. B.; Ortiz, J. V.; Cui, Q.; Baboul, A. G.; Clifford, S.; Cioslowski, J.; Stefanov, B. B.; Liu, G.; Liashenko, A.; Piskorz, P.; Komaromi, I.; Martin, R. L.; Fox, D. J.; Keith, T.; Al-Laham, M. A.; Peng, C. Y.; Nanayakkara, A.; Challacombe, M.; Gill, P. M. W.; Johnson, B.; Chen, W.; Wong, M. W.; Gonzalez, C.; Pople, J. A. Gaussian 03, Revision C.02; Gaussian: Wallingford, CT, 2004.

44. Bawn, C. E. H. The Decomposition of Organic Solids, Chapter 10. In Chemistry in the Solid State; Garner, W. E., Ed.; Butterworths: London, 1955.

45. Brown, M. E.; Glass, B. D. Int. J. Pharm. 2003, 254, 255. 